\title{
New design model of reinforced concrete beams in bending considering the ductility factor
}

\section{Novo modelo de dimensionamento de vigas em concreto armado à flexão simples considerando o fator de ductilidade}
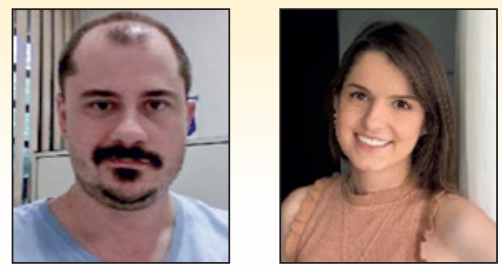

C. G. NOGUEIRA

caio.nogueira@unesp.br https://orcid.org/0000-0002-1888-7637

D. RODRIGUES

isabela.dr@hotmail.com https://orcid.org/0000-0003-2035-9670

\section{Abstract}

Ductility is a recommended characteristic by different RC structures design codes around the world, such as ABNT NBR 6118 [2], ACI 318 [1] and EUROCODE 2 [4]. Despite the recommendation of ductility, the codes only define this criterion in a qualitative way, without quantification about how ductile the structure is, and not being able to stablish a ductility level in the design phase. In this context, this paper proposes a new design model of reinforced concrete beams in bending considering the explicit definition of the input parameter named ductility factor, which quantifies the structure's ability to withstand displacement before it breaks.

Keywords: RC beams, concrete, ductility, damage.

\section{Resumo}

A ductilidade é característica preconizada por diversas normas de projetos de estruturas de concreto armado ao redor do mundo, como ABNT NBR 6118 [2], ACI 318 [1] e EUROCODE 2 [4]. Apesar de exigirem que as estruturas sejam dúcteis, as normas estabelecem esse critério apenas em caráter qualitativo, sem quantificar o quão dúctil a estrutura é, e sem ser capaz de definir um nível de ductilidade na fase de projeto. Nesse contexto, este trabalho propõe um novo modelo de dimensionamento de estruturas de concreto armado sujeitas a flexão simples, a partir da definição explícita do parâmetro de entrada denominado fator de ductilidade, que quantifica a capacidade da estrutura de suportar deslocamentos antes de se romper.

Palavras-chave: vigas em concreto armado, concreto, ductilidade, dano. 


\section{Introduction}

Ductility in a reinforced concrete structural element is defined as the capacity to withstand considerable plastic deformation before rupture, without significant loss of resistance. In the context of a structural system, the ductility of the elements ensures the ability of internal forces redistribution as some cross section reach plasticization. This ductile behaviour avoids sudden ruptures, increasing the security level of the structural systems regarding Ultimate Limit States (Ko et al. [7]; Kara e Ashour [5]).

Regarding design, some recent standards for reinforced concrete structures (ABNT NBR 6118 [2]; EUROCODE 2 [4]; ACI 318 [1]) demand that structural elements ductility is ensured for positive and negative bending moments by restricting the neutral axis position $\left(\beta_{\mathrm{x}}\right)$ on the bending design of critical cross sections of the element. The neutral axis is defined as the geometrical place where all points of the element's cross section have zero normal stresses, dividing the section on a tensile and a compressed region. So, one can define this geometric position during the design process as its relative position on the cross section by $\beta_{x}=x / d$, where $x$ means the distance between the cross section's most compressed fibre and the neutral axis and d means the effective depth of the section. In such way, the neutral axis relative position works as a parameter to indicate the cross-section's ductility on a structural element, since it controls the deformation level of the compressed concrete and the steel of the longitudinal bars. Considering beams, EUROCODE 2 [4] and ABNT NBR 6118 [2] recommend that, to ensure ductility on the ultimate limit state, the neutral axis relative position must be limited as: $\beta_{x} \leq 0,45$ for concretes of $f_{c k} \leq 50 \mathrm{MPa}$ and $\beta_{x} \leq 0,35$ for concretes of $f_{c k}>50 M P a$.

This is an easy approach to be considered in the design phase, since it is defined by a control parameter well know (neutral axis position) during the design process of structural elements. However, several important mechanisms that interfere on the general behaviour of reinforced concrete beams are not considered in an explicit way, like damage evolution and cracking as the loads act in the structure; the confinement effect of the compressed concrete given by the stirrups and the concrete's tensile contribution between cracks (tension stiffening). Different researchers have studied ductility in reinforced concrete elements, and also the plastic hinge capacity in collapse situations, using empirical or numerical models that consider the effects described previously (Teng et al. [15]; Oehlers [11]; Panagiotakos e Fardis [14]; Lopes et al. [9]; Oehlers et al. [13]; Nogueira e Rodrigues [10]). Regarding numerical analysis, the results has been considered trustworthy and with good representation of the experimental answers, especially in the case of regular beams in bending, once the phenomenological behaviour of the materials and the structural elements have been modelled with good precision (Oehlers et al. [12]; Nogueira e Rodrigues [10]; Nogueira et al. [17], Pituba e Lacerda [18]; Pereira Junior et al. [19]). Models of material behaviour based on Continuous Damage Mechanics (Lemaitre e Chaboche [20]) have been frequently used on the numerical analysis of reinforced concrete structures, since they are capable to represent well the damage evolution as a penalizing magnitude for stiffness of reinforced concrete elements. Therefore, the prediction of elements structural response on the
Ultimate Limit State is more accurate, allowing a better evaluation of ductility in that phase.

Although, there are few studies of techniques that can quantify clearly ductility and use it as an information in the design phase of reinforced concrete structural elements. In this context, Lee e Pan [8] studied the explicit quantification of ductility through a factor that links the ultimate curvature and yielding curvature of the cross section of reinforced concrete beams. The factor is a dimensionless measure that quantifies ductility in the cross section of the structural element in the Ultimate Limit State. The approach developed by those authors considered the Kent e Park's model [6] for the compressed concrete and the confinement effect caused by the transversal reinforcement. The developed formulation allowed the reinforced concrete beam's cross-section design from the straight use of a ductility factor as an input parameter chosen by the designer.

This work aims to develop a similar technique to quantify the ductility factor using the constitutive laws for steel and compressed concrete recommended by ABNT NBR 6118 [2], presenting an alternative analytical formulation for the design of the cross-section of reinforced concrete beams in bending, based on the prescription of the ductility factor. The equations have been developed based on traditional concepts that are already used in the design of beams, but using the material models from the Brazilian standard. It is an alternative design model for simple flexure that considers only simple reinforcement, in which the designer adopts, as an input data, the ductility factor of the interest cross-section. A calculation script for the new design model is also presented to settle the formulation.

\section{Mechanical model}

\subsection{Constitutive laws for compressed concrete and steel in tension}

Figures 1 and 2 show the stress $\times$ strain diagram for compressed concrete and for steel in tension, respectively, recommended by ABNT NBR 6118 [2] and used in this study.

For compressed concrete (Figure 1), the Brazilian standard define a linear relation between stress and strain for compression



Figure 1

Constitutive law for compressed concrete in cases that $\mathrm{f}_{\mathrm{ck}} \leq 50 \mathrm{MPa}$ 


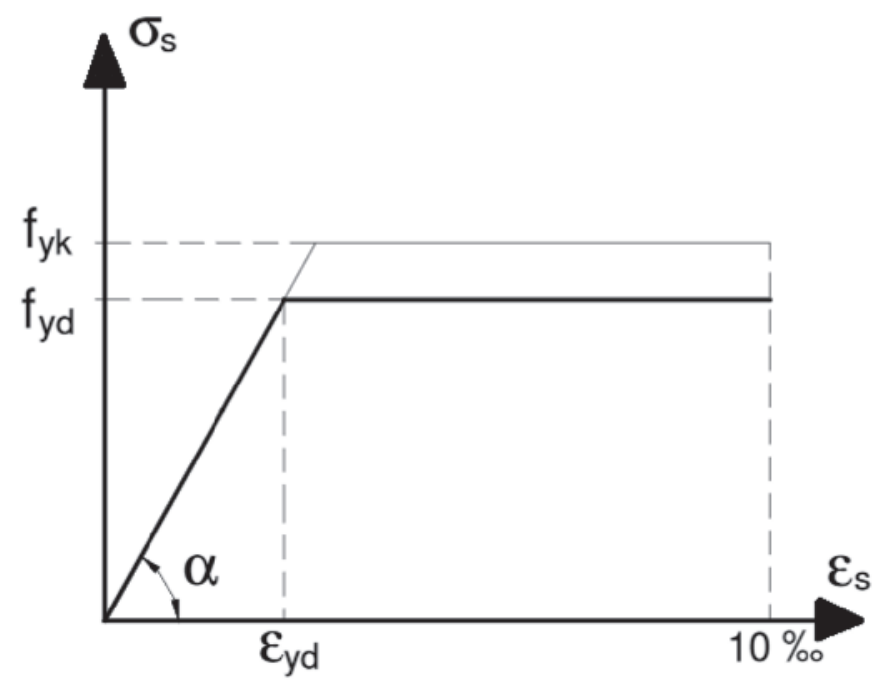

Figure 2

Constitutive law for CA-50 steel

stress smaller than $0,5 f_{c k}$. The diagram consists in a second-degree parabola between the elastic linear phase and the horizontal plateau. Regarding steel, the diagram showed in Figure 2 can be applied to tensile and compression stresses, and it is applicable to temperature ranges between $-20^{\circ} \mathrm{C}$ and $150^{\circ} \mathrm{C}$. The ultimate steel strain is limited to $\varepsilon_{\mathrm{su}}=10 \%$ for tensile and $\varepsilon_{\mathrm{cu}}=3,5 \%$ for compression, which is the same value used for concrete. For CA-50 steel, the design yield strain $\left(\varepsilon_{\mathrm{yd}}\right)$ is considered $2,07 \%$.

\subsection{The ductility factor}

In rupture for bending, the cross-section parameters of the structural element that control the mechanical behaviour are the neutral axis position ( $x$ ) and effective depth (d). Regarding this, rupture can occur in three different ways: failure by tensile in the longitudinal reinforcement, failure by concrete crushing and balanced failure. In the first scenario, the reinforcement yields before the concrete

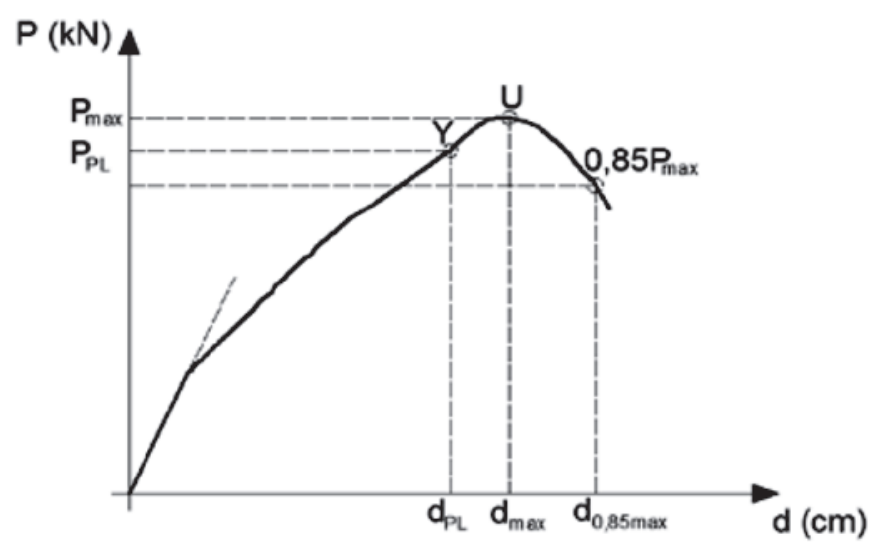

Figure 3

Yielding curvature $(Y)$, ultimate curvature adopted in this work (U) and based on Lopes et al. [9] is crushed (under-reinforced beams), whereas in the second scenario, the concrete crushes before the reinforcement yields (overreinforced beams). On the balanced condition, concrete crush and reinforcement yield happens simultaneously. Considering ductility in the Ultimate Limit State, only for under- reinforced beams, it is possible to observe ductile behaviour with significant deformation before rupture, which avoids brittle failure (MacGregor e Wight [21]). Thus, although the balanced condition is an interesting option, it does not ensure enough ductility for the reinforced concrete cross-sections. For CA-50 steel, the relative neutral axis position that indicates the balanced condition is $\beta_{x}=0,628$. This value is no more allowed by ABNT NBR 6118 (2014) for Ultimate Limit State design once it does not ensure enough ductile behaviour to reinforced concrete elements. Therefore, it is necessary to define a measure to explicitly quantify ductility and, at the same time, use it to directly design cross-sections in terms of effective depth and tensile reinforcement area.

The ductility factor $\left(\mu_{\varphi}\right)$ of the cross-section (Lee e Pan [8]) is defined as the relationship between ultimate curvature $\left(\varphi_{u}\right)$ and yielding curvature $\left(\varphi_{\mathrm{y}}\right)$, as in:

$\mu_{\phi}=\frac{\phi_{u}}{\phi_{y}}$

The yielding curvature is defined when the longitudinal reinforcement reaches the yielding stress of steel and plasticizes on the analysed cross-section. The ultimate curvature, also defined in the same cross-section, has different definitions on the literature based on each researcher's opinion. Ziara et al. [16], based on experimental investigation on reinforced concrete beams in bending, defines ultimate curvature as the one that happens when the deformation of the compressed concrete fibre placed in the same position of the longitudinal compression reinforcement reaches $5,0 \%$, meaning that this approach allows compressed concrete strain values to overcome the limit of $3,5 \%$ defined for flexure. The consequence of this consideration is that the bending moment associated with this strain level is different from the ultimate value as a bending resistance capacity. Lopes et al. [9] consider ultimate curvature of the cross-section as the one corresponding to $85 \%$ of the resistant bending moment after the post peak of the equilibrium trajectory is achieved.

In this work, based on the necessity to develop an analytical formulation consistent with the traditional hypotheses established for the design of reinforced concrete beams in bending, the ultimate curvature will be considered as the one associated with ultimate bending moment that defines the resistant capacity of the cross-section. This way, the ultimate strain admitted for concrete in the most compressed fibre of the section will be $3,5 \%$ and it is admitted that, on this condition, the ultimate bending moment is reached. Figure 3 shows the approaches described here on a force $\times$ displacement diagram for reinforced concrete beams in bending.

\section{Design formulation based on the ductility factor}

The developed formulation can be applied on the design of reinforced concrete beams with rectangular cross-section, considering the simplicity of the parable-rectangle diagram showed in Figure 1 

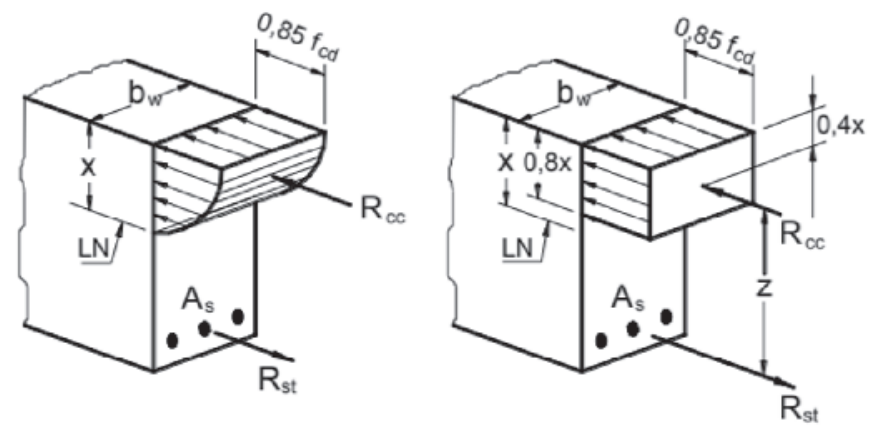

Figure 4

Distribution of compression stresses on concrete considering the parable rectangle diagram (left) and simplified rectangular (right) (Bastos [3])

for the rectangular one, in which the plasticized concrete zone has an extension of $80 \%$ of the neutral axis position (x). Figure 4 shows the adopted simplification.

Figure 5 shows the scheme that describes the longitudinal strains compatibility over the cross-section height of a reinforced concrete beam element.

Regarding Euler-Bernoulli theory and in small strain domain, the specific longitudinal strain in any fibre positioned above the neutral axis can be calculated by Equation (2).

$\operatorname{tg} \phi \cong \phi=\frac{\varepsilon}{d-x}$

Where $\varphi$ is the curvature of the cross-section; $d$ is the effective depth; $x$ is the neutral axis position; $\varepsilon$ corresponds to the longitudinal strain on the analysed fibre. On the fibre where the longitudina reinforcement is placed, $\varepsilon=\varepsilon_{\text {sd }}$.

Describing the neutral axis on its dimensionless form, Equation (2) can be rewritten in Equation (3).

$\beta_{x}=\frac{x}{d} \quad \rightarrow \quad x=\beta_{x} d$

Arranging equations (2) and (3), one achieve Equations (4) and (5) that describes, respectively, the cross-section curvature in terms of longitudinal reinforcement in tensile strain and yielding curvature, when the reinforcement reaches the yield stress of steel.

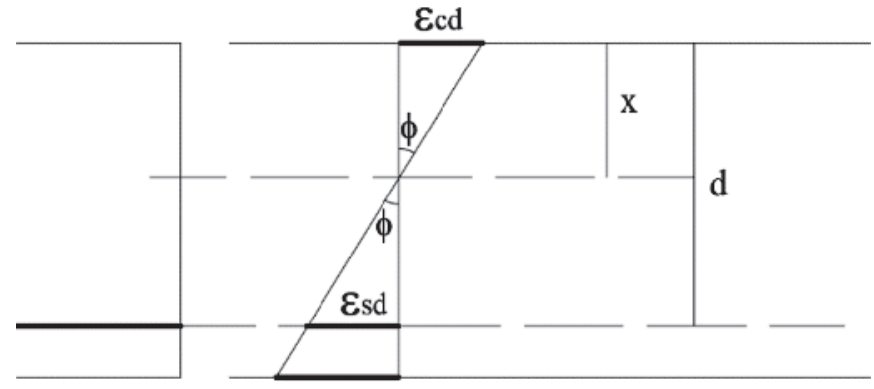

\section{Figure 5}

Longitudinal strain compatibility

$\phi=\frac{\varepsilon_{s d}}{d\left(1-\beta_{x}\right)}$

$\phi_{y}=\frac{\varepsilon_{y d}}{d\left(1-\beta_{x}\right)}=\frac{f_{y d} / E_{s}}{d\left(1-\beta_{x}\right)}$

Where $\beta_{\mathrm{x}}$ is the neutral axis relative position; $\varepsilon_{\mathrm{yd}}$ and $\mathrm{f}_{\mathrm{yd}}$ are, respectively, the yield strain and yield stress of longitudinal reinforcement steel; $E_{s}$ is the longitudinal modulus of elasticity.

The cross-section curvature can also be written based on the observed strain fibres above the neutral axis. Considering the most compressed concrete fibre, the curvature is defined as:

$\phi=\frac{\varepsilon_{c d}}{\beta_{x} d}$

Based on the hypotheses adopted in this study, the ultimate curvature of the cross-section can be written in terms of ultimate compressed concrete strain $\left(\varepsilon_{\mathrm{cu}}\right)$ on the most external fibre, as in Equation (7).

$\phi_{u}=\frac{\varepsilon_{c u}}{\beta_{x} d}$

The design of reinforced concrete beams submitted to bending moment is defined based on the equilibrium of normal forces and bending moments, as shown in Figure 6.

TThe parts corresponding to the resulting compression force on concrete $\left(R_{c c}\right)$ and tensile on the longitudinal reinforcement $\left(R_{s t}\right)$ are calculated based on Equations (8) and (9).

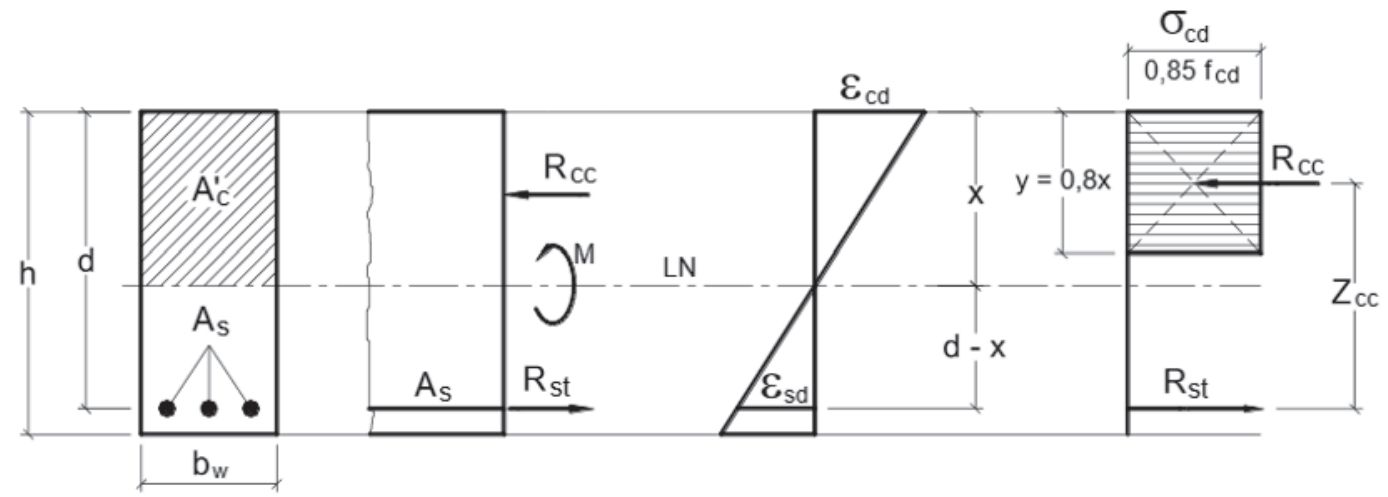

Figure 6

Longitudinal strain diagram and normal stress used for Ultimate Limit State design (Bastos [3]) 
$R_{c c}=0,85 f_{c d} 0,8 \beta_{x} d b_{w}=0,68 b_{w} \beta_{x} d f_{c d}$

$R_{s t}=f_{y} A_{s}$

In order to get the equilibrium of normal forces on the cross-section, the forces on the concrete and steel (Equations 8 and 9) must be the same. Putting it together on equilibrium and rewriting it properly, one achieves Equation (10).

$0,68 \beta_{x} f_{c d}=f_{y} \frac{A_{s}}{b_{w} d}$

Where $f_{c d}$ is the design resistance of concrete in compression; $f_{y}$ is the normal stress on the tensile longitudinal reinforcement; $b \_w$ is the cross-section width; $A_{s}$ is the area of tensile reinforcement. Writing the longitudinal reinforcement ratio $\left(\rho_{s}\right)$ as $\rho_{s}=A_{s} /\left(b_{w} d\right)$, Equation (10) gives the tensile reinforcement ratio according to Equation (11).

$\rho_{s}=\frac{0,68 \beta_{x} f_{c d}}{f_{y}}$

Matching the expressions that define the cross-section curvature given by Equations (4) and (6) and isolating the neutral axis relative position, Equations (12) and (13) are obtained.

$$
\begin{aligned}
& \frac{\varepsilon_{s d}}{d\left(1-\beta_{x}\right)}=\frac{\varepsilon_{c d}}{\beta_{x} d} \\
& \beta_{x}=\frac{\varepsilon_{c d}}{\left(\varepsilon_{s d}+\varepsilon_{c d}\right)}
\end{aligned}
$$

Replacing (13) in (11) makes it possible to write the ratio of tensile longitudinal reinforcement only considering the material stresses and the strain level at them, as in:

$\rho_{s}=\frac{0,68 \varepsilon_{c d} f_{c d}}{\left(\varepsilon_{s d}+\varepsilon_{c d}\right) f_{y}}$

To put in the same expression the ductility factor and the tensile longitudinal reinforcement ratio, the neutral axis relative position can be explicit obtained based on Equation (11) by $\beta_{x}=\left(\rho_{s y}\right) /\left(0,68 f_{c d}\right)$ and replaced in (15). Also, since it may be considered domains 2 and 3 in the design of beams, the normal stress in the tensile reinforcement must be equal to the yield stress of steel, which results in $f_{y}=f_{y d}$. By these, the tensile longitudinal reinforcement ratio based on the ductility factor can be written as in Equation (15). $\mu_{\phi}=\frac{\phi_{u}}{\phi_{y}}=\frac{\varepsilon_{c u}}{\beta_{x} d} \times \frac{d\left(1-\beta_{x}\right)}{\varepsilon_{y d}}=\frac{\varepsilon_{c u}\left(1-\beta_{x}\right)}{\beta_{x} \varepsilon_{y d}}$

Rewriting (16) and isolating the reinforcement ratio, there are Equations (17) and (18).

$\mu_{\phi}=\frac{\varepsilon_{c u}\left(1-\frac{\rho_{s} f_{y d}}{0,68 f_{c d}}\right)}{\frac{\rho_{s} f_{y d}}{0,68 f_{c d}} \varepsilon_{y d}}$

$\mu_{\phi}=\left(\varepsilon_{c u}-\frac{\varepsilon_{c u} \rho_{s} f_{y d}}{0,68 f_{c d}}\right) \times \frac{0,68 f_{c d}}{\rho_{s} f_{y d} \varepsilon_{y d}}=\frac{0,68 \varepsilon_{c u} f_{c d}}{\rho_{s} f_{y d} \varepsilon_{y d}}-\frac{\varepsilon_{c u}}{\varepsilon_{y d}}$

$\mu_{\phi}=\frac{\varepsilon_{c u}}{\varepsilon_{y d}}\left(\frac{0,68 f_{c d}}{\rho_{s} f_{y d}}-1\right)$

$\frac{\mu_{\phi} \varepsilon_{y d}}{\varepsilon_{c u}}=\frac{0,68 f_{c d}}{\rho_{s} f_{y d}}-1$

$\frac{\mu_{\phi} \varepsilon_{y d}}{\varepsilon_{c u}}+1=\frac{0,68 f_{c d}}{\rho_{s} f_{y d}}$

$\frac{\mu_{\phi} \varepsilon_{y d}+\varepsilon_{c u}}{\varepsilon_{c u}}=\frac{0,68 f_{c d}}{\rho_{s} f_{y d}}$

$\rho_{s}=\frac{0,68 f_{c d} \varepsilon_{c u}}{f_{y d}\left(\mu_{\phi} \varepsilon_{y d}+\varepsilon_{c u}\right)}$

Equation (18) shows the final relationship between tensile longitudinal reinforcement ratio and the ductility factor. By these, a convenient dimensionless value for $\mu_{\varphi}$ in the design can be adopted and, based on (18), the properly tensile reinforcement ratio in the analysed cross-section is achieved.

\section{Comparison between the developed model and Lee and Pan's model [8]}

The analytical model proposed by Lee and Pan [8] sets also a straight relationship between the longitudinal reinforcement ration and the ductility factor. It can be expressed, in a simplified expression, as $\rho_{\mathrm{s}}=F\left(\mu_{\mathrm{o}}\right)^{\mathrm{G}}$, in which the coefficients $F$ and $G$ have been obtained by linear regression based on several sets of typical RC beams. The differences between Lee and Pan's model [8] and the proposed formulation at this work can be observed in Table 1.

\section{Table 1}

Comparison between the formulations $\rho_{s}=f\left(\mu_{\varphi}\right)$

\section{Lee and Pan's model [8]}

Constitutive law for the compressed concrete based on Kent and Park (1971) with a post peak softening branch

Possibility of considering the compressed reinforcement on the cross section

Possibility of considering the confinement effect without the increase of compressed resistance produced by the transversal reinforcement

\section{Proposed model}

Constitutive law for the compressed concrete defined by the parable rectangle diagram ${ }^{1}$ with ultimate strain $\varepsilon_{c u}=3,5 \%$ and without consideration of the post peak softening branch

Considers only the simple tensile reinforcement on the cross section

Do not consider the confinement effect of concrete produced by the longitudinal reinforcement

Comparative tests considering the parable rectangle diagram and the simplified rectangle diagram show that the compression resultant force ( $\left.R_{c c}\right)$ on the concrete's compressed cross section are practically the same (Table 2). This justifies the adoption of the simplified rectangle diagram for the equilibrium, once the differences are negligible.

2 The stirrups are placed in an ordinary way, which means in the whole cross section high. Stirrups only in the compressed portion of the cross-section are not considered. The confinement effect considered influences only in the post peak part of the stress $x$ strain diagram of compressed concrete, do not providing increase of concrete's resistance. 
The comparison between both models was performed considering the following parameters: rectangular cross-section with $b_{w}=15 \mathrm{~cm}$ and $d=35 \mathrm{~cm}$; CA-50 steel with $\mathrm{f}_{\mathrm{yd}}=435 \mathrm{MPa}$ and $\varepsilon_{\mathrm{yd}}=2,07 \%$; no compression reinforcement; concrete cover of $\mathrm{c}=2 \mathrm{~cm}$; compressed concrete resistance classes C20, C30, C40 and C50; for the proposed model: : $\varepsilon_{\mathrm{cu}}=3,5 \%$ and $\varepsilon_{0}=2,0 \%$; for Lee and Pan's model [8]: $\varepsilon_{\mathrm{cu}}=5,0 \%$ e $\varepsilon_{0}=2,0 \%$; transversal reinforcement with conventional stirrups of $\varphi_{\mathrm{sw}}=5 \mathrm{~mm}$ each $10 \mathrm{~cm}$. Figure 7 shows the results obtained based on the comparison between $\mu_{\varphi} \times \rho_{\mathrm{s}}$ diagrams for the four concrete classes. The subtitle on the diagrams corresponds to: "DR" proposed model with rectangular diagram; "L P.sc" Lee and Pan's model [8] without confinement; "L P.cc" Lee and Pan's model with confinement.

Table 2 shows the results for the proposed model obtained with the parameters that were described above and for concrete C20, comparing the simplification of the rectangular diagram (D.R.) of stresses on the compressed concrete with the parable rectangle (D.P.R.). The comparison is between the tensile longitudinal reinforcement ratio and the resulting compression force on the concrete $\left(R_{c c}\right)$ for different values of the ductility factor $\left(\mu_{\varphi}\right)$ associated to the respective relative neutral axis position $\left(\beta_{\mathrm{x}}\right)$.

As observed, the resulting values of compression force for the D.R. and D.P.R. cases are close to each other, justifying the use of the simplified rectangular diagram for stresses in the formulation of the proposed model. In the same way, the values of tensile longitudinal reinforcement ratio for both diagrams also showed themselves similar. As far as the relative neutral axis position decreases, the ductility factor obtained in the design increases. This is in accordance with the recommendations from the design standards to limit the beam's ductility.

For $\beta_{x}=0,458$ on class $\mathrm{C} 20$, the calculated ductility factor is $\mu_{\varphi}=2$, indicating that this is the measure of ductility imposed by ABNT NBR 6118 [2] when the neutral axis relative position is limit in 0,450 for concrete with compressed resistance smaller than $50 \mathrm{MPa}$.

In Figure 7, the results obtained with the proposed model where in the middle of Lee and Pan's formulation [8] with and without confinement. Comparing only the results of both models without confinement, the proposed model in this work, even if simplified, showed good match with Lee and Pan's model [8]. As the concrete compression resistance increases, in order to keep the same ductility factor, it is necessary to increase the reinforcement ratio.

\section{Appling the proposed model on the design of a beam}

\subsection{Isostatic Beam}

Figure 8 shows the static scheme of a simply supported beam with $6,72 \mathrm{~m}$ of free spam, subjected to a uniform load and a concentrated force positioned at $3,18 \mathrm{~m}$ of the left support.

The adopted data to solve the problem was: $b_{w}=14 \mathrm{~cm} ; \mathrm{h}=70 \mathrm{~cm}$; $\mathrm{d}=65 \mathrm{~cm} ; \mathrm{f}_{\mathrm{ck}}=25 \mathrm{MPa} ; \mathrm{f}_{\mathrm{yk}}=500 \mathrm{MPa} ; \gamma_{\mathrm{c}}=1,4 ; \gamma_{\mathrm{s}}=1,15 ; \gamma_{\mathrm{f}}=1,4$.


Figure 7

Comparison between $\mu_{\varphi} \times \rho_{\mathrm{s}}$ diagrams for concrete classes C20, C30, C40 and C50 


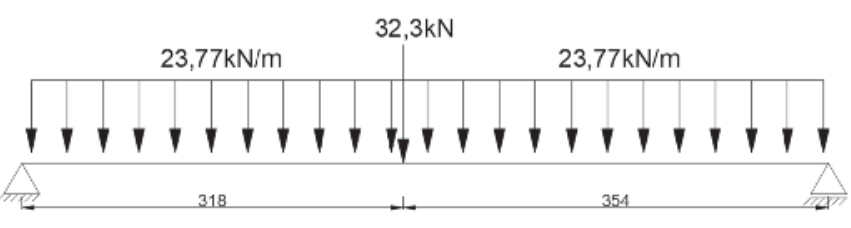

Figure 8

Static scheme of the analysed beam (units in centimetre)

The results were obtained for the cross section subjected to the maximum bending moment, considering only the longitudinal reinforcement from the standard procedure. Although it is a known process in structural design, the steps are shown for a comparison with the described procedure in the proposed model. The ductility factor $\left(\mu_{\varphi}\right)$ obtained was 2,0 .

$$
\text { Input data: } M_{k} ; b_{w} ; d ; f_{c k} ; f_{y k} ; \gamma_{c} ; \gamma_{s} ; \gamma_{f}
$$

Step 1: Calculation of the neutral axis relative position with the equilibrium equation:

$$
\begin{gathered}
\gamma_{f} M_{k}=0,68 b_{w} d^{2} \beta_{x} f_{c d}\left(1-0,4 \beta_{x}\right) \\
1,4 \times 19012,4=0,68 \times 14 \times 65^{2} \times \frac{2,5}{1,4}\left(1-0,4 \times \beta_{x}\right) \\
\beta_{x}=0,452
\end{gathered}
$$

Step 2: Calculation of the tensile longitudinal reinforcement area:

$$
A_{s}=\frac{0,68 b_{w} d f_{c d} \beta_{x}}{f_{y d}}=\frac{0,68 \times 14 \times 65 \times \frac{2,5}{1,4} \times 0,452}{\frac{50}{1,15}}=11,48 \mathrm{~cm}^{2}
$$

Check: Calculation of the tensile longitudinal reinforcement rate:

$$
\rho_{s}=\frac{A_{s}}{b_{w} d}=\frac{11,48}{14 \times 65}=0,0126
$$

Check: Calculation of the ductility factor (Equation 18):

$$
\begin{gathered}
\rho_{s}=\frac{0,68 f_{c d} \varepsilon_{c u}}{f_{y d}\left(\mu_{\phi} \varepsilon_{y d}+\varepsilon_{c u}\right)} \rightarrow 0,0126=\frac{0,68 \times\left(\frac{2,5}{1,4}\right) \times 0,0035}{\frac{50}{1,15} \times\left(\boldsymbol{\mu}_{\phi} \times 0,00207+0,0035\right)} \\
\boldsymbol{\mu}_{\boldsymbol{\phi}}=\mathbf{2 , 0}
\end{gathered}
$$

To perform a comparison, the same process is done considering the new design model based on the explicit choice of the ductility factor 2,0. The steps of the new design model are shown based on the ductility definition for the analysed cross-section. The results obtained with both design models are practically the same. However, with the

\begin{tabular}{|c|c|c|c|c|c|}
\hline$\mu_{\varphi}$ & $\beta_{x}$ & $\rho_{s}$ (D.R.) & $\begin{array}{l}\mathbf{R}_{\text {C D D.R. }} \\
(\mathrm{N})\end{array}$ & $\rho_{s}$ (D.P.R.) & $\begin{array}{l}R_{C C D . P R} \\
(\mathrm{~N})\end{array}$ \\
\hline 1 & 0.628 & 0.0196 & 4486.5 & 0.0199 & 4539.9 \\
\hline 2 & 0.458 & 0.0143 & 3270.9 & 0.0145 & 3309.9 \\
\hline 3 & 0.360 & 0.0113 & 2573.6 & 0.0114 & 2604.3 \\
\hline 4 & 0.297 & 0.0093 & 2121.4 & 0.0094 & 2146.6 \\
\hline 5 & 0.253 & 0.0079 & 1804.3 & 0.0080 & 1825.8 \\
\hline 6 & 0.220 & 0.0069 & 1569.7 & 0.0070 & 1588.4 \\
\hline 7 & 0.195 & 0.0061 & 1389.1 & 0.0062 & 1405.6 \\
\hline 8 & 0.174 & 0.0055 & 1245.8 & 0.0055 & 1260.6 \\
\hline 9 & 0.158 & 0.0049 & 1129.2 & 0.0050 & 1142.7 \\
\hline 10 & 0.145 & 0.0045 & 1032.6 & 0.0046 & 1044.9 \\
\hline 11 & 0.133 & 0.0042 & 951.3 & 0.0042 & 962.6 \\
\hline 12 & 0.124 & 0.0039 & 881.8 & 0.0039 & 892.3 \\
\hline 13 & 0.115 & 0.0036 & 821.8 & 0.0036 & 831.6 \\
\hline 14 & 0.108 & 0.0034 & 769.4 & 0.0034 & 778.6 \\
\hline 15 & 0.101 & 0.0032 & 723.3 & 0.0032 & 731.9 \\
\hline 16 & 0.096 & 0.0030 & 682.4 & 0.0030 & 690.5 \\
\hline 17 & 0.090 & 0.0028 & 645.9 & 0.0029 & 653.6 \\
\hline 18 & 0.086 & 0.0027 & 613.1 & 0.0027 & 620.4 \\
\hline 19 & 0.082 & 0.0026 & 583.5 & 0.0026 & 590.4 \\
\hline 20 & 0.078 & 0.0024 & 556.6 & 0.0025 & 563.2 \\
\hline 21 & 0.075 & 0.0023 & 532.0 & 0.0024 & 538.4 \\
\hline 22 & 0.071 & 0.0022 & 509.6 & 0.0023 & 515.7 \\
\hline 23 & 0.068 & 0.0021 & 488.9 & 0.0022 & 494.8 \\
\hline 24 & 0.066 & 0.0021 & 469.9 & 0.0021 & 475.5 \\
\hline 25 & 0.063 & 0.0020 & 452.3 & 0.0020 & 457.7 \\
\hline
\end{tabular}
new procedure it is possible to specify explicitly the desirable ductility factor of the cross-section of the reinforced concrete element.

$$
\text { Input data: } M_{k} ; b_{w} ; f_{c k} ; f_{y k} ; \gamma_{c} ; \gamma_{s} ; \gamma_{f} ; \boldsymbol{\mu}_{\boldsymbol{\phi}}=\mathbf{2 , 0}
$$

Step 1: Calculation of the tensile longitudinal reinforcement area (Equation 18):

\section{Table 2}

Comparison of results for concrete $\mathrm{C} 2 \mathrm{O}$ 


$$
\rho_{s}=\frac{0,68 f_{c d} \varepsilon_{c u}}{f_{y d}\left(\mu_{\phi} \varepsilon_{y d}+\varepsilon_{c u}\right)}=\frac{0,68 \times\left(\frac{2,5}{1,4}\right) \times 0,0035}{\frac{50}{1,15} \times(2,0 \times 0,00207+0,0035)}=0,0127
$$

Step 2: Calculation of the relative neutral axis position (Equation 11):

$$
\beta_{x}=\frac{\rho_{s} f_{y d}}{0,68 f_{c d}}=\frac{0,0127 \times \frac{50}{1,15}}{0,68 \times \frac{2,5}{1,4}}=0,454
$$

Step 3: Calculation of the effective depth of the cross section by the equilibrium equation:

$$
\begin{aligned}
d=\sqrt{\frac{\gamma_{f} M_{k}}{0,68 b_{w} \beta_{x} f_{c d}\left(1-0,4 \beta_{x}\right)}}=\sqrt{\frac{1,4 \times 19012,4}{0,68 \times 14 \times 0,454 \times \frac{2,5}{1,14} \times(1-0,4 \times 0,454)}} \\
d=64,91 \cong 65 \mathrm{~cm}
\end{aligned}
$$

Step 4: calculation of the tensile longitudinal reinforcement area:

$$
A_{s}=\rho_{s} b_{w} d=0,0127 \times 14 \times 65=11,55 \mathrm{~cm}^{2}
$$

Considering the same informed data previously, it is presented the beam's cross-section design for a ductility factor of 5,0 .

Input data: $M_{k} ; b_{w} ; f_{c k} ; f_{y k} ; \gamma_{c} ; \gamma_{s} ; \gamma_{f} ; \boldsymbol{\mu}_{\boldsymbol{\phi}}=\mathbf{5 , 0}$

Step 1: Calculation of the tensile longitudinal reinforcement area (Equation 18):

$$
\rho_{s}=\frac{0,68 f_{c d} \varepsilon_{c u}}{f_{y d}\left(\mu_{\phi} \varepsilon_{y d}+\varepsilon_{c u}\right)}=\frac{0,68 \times\left(\frac{2,5}{1,4}\right) \times 0,0035}{\frac{50}{1,15} \times(\mathbf{5 , 0} \times 0,00207+0,0035)}=0,00706
$$

Step 2: Calculation of the relative neutral axis position (Equation 11):

$$
\beta_{x}=\frac{\rho_{s} f_{y d}}{0,68 f_{c d}}=\frac{0,00706 \times \frac{50}{1,15}}{0,68 \times \frac{2,5}{1,4}}=0,253
$$

Step 3: Calculation of the effective depth of the cross section by the equilibrium equation:

$$
\begin{aligned}
d=\sqrt{\frac{\gamma_{f} M_{k}}{0,68 b_{w} \beta_{x} f_{c d}\left(1-0,4 \beta_{x}\right)}} & =\sqrt{\frac{1,4 \times 19012,4}{0,68 \times 14 \times 0,253 \times \frac{2,5}{1,14} \times(1-0,4 \times 0,253)}} \\
d & =82,97 \cong 83 \mathrm{~cm}
\end{aligned}
$$

Step 4: Calculation of the tensile longitudinal reinforcement area:

$$
A_{s}=\rho_{s} b_{w} d=0,00706 \times 14 \times 83=8,20 \mathrm{~cm}^{2}
$$

On that case, to increase ductility, it is necessary to decrease the relative neutral axis position and, consequently, decrease the longitudinal reinforcement ratio. Thus, to make it happen, it is necessary to increase the cross section height, which is coherent with the actual design practice in reinforced concrete beams.

Figure 9 shows the behaviour of the relative neutral axis position as far as the ductility factor varies. According to the model's formulation, the value of the ductility factor associated with the neutral axis position is constant, independently of the concrete resistance class. On that way, there is a unique and constant relation between $\mu_{\varphi}$ and $\beta_{x}$. The concrete resistance class interferes only on the amount of reinforcement and on the effective depth of the cross section to provide the same ductility factor, independently of the neutral axis. This behaviour is in accordance with



\section{Figure 9}

Relationship between the ductility factor and relative neutral axis position
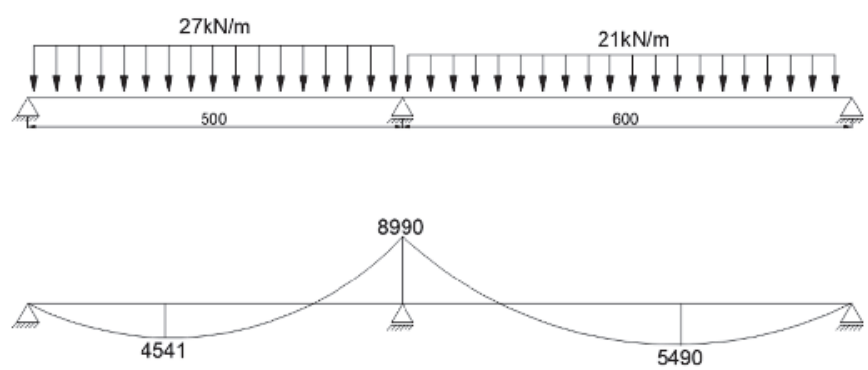

Figure 10

Static scheme of the analysed beam (units and centimetre) and bending moment diagram (units in $\mathrm{kNcm}$ )

the design standards recommendations when they impose a restriction on the relative neutral axis position to ensure the ductility of the element. For $\beta_{x}=0,450$, which is the limit imposed by the Brazilian standard for concrete until $50 \mathrm{MPa}$, the ductility factor is 2,07 . On the other hand, when the neutral axis position is on the limit between domains 2 and $3\left(\beta_{x}=0,259\right)$, the ductility factor associated is 4,83 . This establishes a range to define the values of $\mu_{\varphi}$ for the design of reinforced concrete beams in bending. It is evident that in cases of elevate values for the ductility factor, the beam's cross-section tends to have bigger height, based on the tensile longitudinal reinforcement ratio. On these situations, the neutral axis position might increase over the cross section height, decreasing even more the compressed part of concrete. This behaviour is similar to a reinforced concrete tie, where only the steel have a structural function and the concrete only protects the steel from the environment.

\subsection{Hyperstatic beam}

Figure 10 shows the static scheme and the bending moment diagram of a two-span beam subjected to different loads.

The adopted data to solve the problem was: $b_{w}=14 \mathrm{~cm} ; \mathrm{h}=50 \mathrm{~cm}$; $\mathrm{d}=45 \mathrm{~cm} ; \mathrm{f}_{\mathrm{ck}}=25 \mathrm{MPa} ; \mathrm{f}_{\mathrm{yk}}=500 \mathrm{MPa} ; \gamma_{\mathrm{c}}=1,4 ; \gamma_{\mathrm{s}}=1,15$; 
Table 3

Conventional design to bending for the hyperstatic beam: $\beta_{x}$ is adopted and $\mu_{\varphi}$ is calculated

\begin{tabular}{cccccc}
\hline S.T. & $\mathbf{M}_{\mathbf{d}}(\mathbf{k N c m})$ & $\beta_{\mathrm{x}}$ & $\mathbf{A}_{\mathbf{s}}\left(\mathbf{c m}^{2}\right)$ & $\rho_{\mathrm{s}}$ & $\mu_{\varphi}$ \\
\hline $\mathrm{M}_{k}=8990$ & 12586 & 0.438 & 7.71 & 0.01224 & 2.17 \\
$\mathrm{M}_{k}=4541$ & 6357 & 0.2014 & 3.53 & 0.00560 & 6.72 \\
$\mathrm{M}_{k}=5490$ & 7686 & 0.248 & 4.36 & 0.00692 & 5.13 \\
\hline
\end{tabular}

Table 4

Conventional design to bending for the hyperstatic beam: $\mu_{\varphi}$ is adopted and $\mu_{\varphi}$ is calculated

\begin{tabular}{ccccccc}
\hline S.T. & $\mathbf{M}_{\mathrm{d}}(\mathbf{k N c m})$ & $\mu_{\varphi}$ & $\rho_{\mathrm{s}}$ & $\beta_{\mathrm{x}}$ & $\mathbf{d}(\mathbf{c m})$ & $\mathbf{A}_{\mathbf{s}}(\mathbf{c m})^{2}$ \\
\hline $\mathrm{M}_{\mathrm{k}}=8990$ & 12586 & 2.17 & 0.01223 & 0.438 & 45.20 & 7.71 \\
$\mathrm{M}_{\mathrm{k}}=4541$ & 6357 & 6.72 & 0.00561 & 0.2014 & 44.98 & 3.53 \\
$\mathrm{M}_{\mathrm{k}}=5490$ & 7686 & 5.13 & 0.00692 & 0.248 & 44.99 & 4.36 \\
\hline
\end{tabular}

$\gamma_{\mathrm{f}}=1,4$. Tables 3 and 4 show, respectively, the design results for the cross sections on bending by the traditional method and by the proposed method via ductility factor. In order to compare the results, the ductility factor was chosen as the same obtained on the traditional calculation.

The differences between the results from the two models can be negligible. It is important to emphasise that for the three analysed cross sections by the proposed model, the effective depth of the beam is almost the same, i.e. $d \approx 45 \mathrm{~cm}$, recovering the value defined on the pre-design phase. All the procedures on the bending moment diagram to obtain the anchorage lengths of the reinforcement bars and other prescriptions on the design of the beams remain the same, being executed in the same way.

Now, let us consider the design of the same hyperstatic beam showed in Figure 10, in which the proposed model via ductility factor is adopted. By imposing the $\mu_{0}$ value over a specific cross section, the values of longitudinal reinforcement ratio, neutral axis relative position, effective depth and tensile reinforcement area were assessed. However, for the other cross sections of the beam, it is not possible to impose the ductility factor in an independent way, because it would produce a new effective depth for the beam associated to that cross section. Therefore, the procedure may choose the ductility factor for the interested cross section and with the obtained effective depth the design is normally done to the other cross sections of the element. This procedure is shown in Table 5, using the ductility factor of 3,0 for the cross section of maximum negative bending moment (8990 $\mathrm{kNcm}$ ) and designing the other sections by the conventional method. Cross sections 2 and 3 were designed considering the effective depth of $49 \mathrm{~cm}$, showing improvement on the ductility factor in comparison to the previous beam $(\mathrm{d}=45 \mathrm{~cm})$ from $25 \%$ and $28 \%$, respectively. It is important to emphasise that this performance, in terms of ductility, for the cross section submitted to positive bending moments, \} decreased almost $10 \%$ the reinforcement area of both sections.

\section{Systematic script for the design with the proposed model}

A systematic script to use the developed model on the design of reinforced concrete beams subjected to bending moments, with simple reinforcement and CA-50 steel is presented. The steps are sequential, based on the definition of the input data and the chosen ductility factor $\left(\mu_{\varphi}\right)$.

Input data: $\mathrm{M}_{\mathrm{k}} ; \mathrm{b}_{\mathrm{w}} ; \mathrm{f}_{\mathrm{ck}} ; \mathrm{f}_{\mathrm{yk}} ; \gamma_{\mathrm{c}} ; \gamma_{\mathrm{s}} ; \gamma_{\mathrm{f}} ; \mu_{\varphi}$;

- Step 1: Calculation of the tensile longitudinal reinforcement rate:

$$
\rho_{s}=\frac{0,68 f_{c d} \varepsilon_{c u}}{f_{y d}\left(\mu_{\phi} \varepsilon_{y d}+\varepsilon_{c u}\right)}
$$

Step 2: Calculation of the relative neutral axis position:

$$
\beta_{x}=\frac{\rho_{s} f_{y d}}{0,68 f_{c d}}
$$

Step 3: Calculation of the effective depth:

$$
d=\sqrt{\frac{\gamma_{f} M_{k}}{0,68 b_{w} \beta_{x} f_{c d}\left(1-0,4 \beta_{x}\right)}}
$$

Step 4: Calculation of the tensile longitudinal reinforcement area:

$$
A_{s}=\rho_{s} b_{w} d
$$

All the parameters involved were defined previously on this paper.

\section{Conclusions}

This paper presented the development of an analytical formulation for a design model to reinforced concrete beams subjected

\section{Table 5}

Proposed model's design for bending of the hyperstatic beam: $\mu_{\varphi}$ is adopted and $\mu_{\varphi}$ is calculated

\begin{tabular}{ccccccc}
\hline S.T. & $\mathbf{M}_{\mathbf{d}}(\mathbf{k N c m})$ & $\mu_{\varphi}$ & $\rho_{s}$ & $\beta_{\mathbf{x}}$ & $\mathbf{d}(\mathbf{c m})$ & $\left.\mathbf{A}_{\mathbf{s}}(\mathbf{c m})^{2}\right)$ \\
\hline$M_{k}=8990$ & 12586 & 3.00 & 0.01007 & 0.360 & 49.01 & 6.91 \\
$M_{k}=4541$ & 6357 & 8.43 & 0.00466 & 0.167 & 49.01 & 3.20 \\
$M_{k}=5490$ & 7686 & 6.56 & 0.00573 & 0.205 & 49.01 & 3.93 \\
\hline
\end{tabular}


to bending moments with simple reinforcement, considering the ductility factor as an input parameter. It is also possible with the proposed model to design traditionally the beam's cross section and get the ductility factors for the designed sections. The compression reinforcement was not introduced in the proposed model. The conclusions obtained in this paper are presented:

- The ductility factor is directly associated to the neutral axis relative position. Therefore, its evaluation is independent of the concrete compression resistance, as observed on the analysed cases with concrete from group 1 specified by the Brazilian standard $\left(f_{c k} \leq 50 \mathrm{MPa}\right)$. Thus, for different concrete compression resistances, in order to have the same ductility of the analysed cross section, the proposed model calculates the effective depth and the tensile longitudinal reinforcement rate that ensures the specified ductility factor. This matches with the recommendations from ABNT NBR 6118 [2] that allows to specify, for example, any value of neutral axis relative position that fulfils an imposed limit independently from the concrete compression resistance;

- The relationship obtained for the longitudinal reinforcement rate and the ductility factor showed in agreement with the obtained results with Lee and Pan's model [8], which considers the concrete post peak softening branch behaviour. Besides, in the proposed model by Lee and Pan [8], it is possible to consider the confinement effect produced by the transversal reinforcement of the beam. This effect is considered from a softening of the descending post peak part of the stress $\times$ strain diagram of compressed concrete from Kent and Park's law [6]. That increases the ductility on the cross sections of beams in the Ultimate Limit State. The proposed model on this study do not admit any descendent part post peak for the compressed concrete, since it considers the compressed concrete behaviour from the stress $\times$ strain diagram depicted in Figure 1. From this, the obtained results with the proposed model show an agreement with these obtained by Lee and Pan's model [8] when the confinement effect is taken into account, as observed in Figure 7;

- Appling the proposed model, it is possible to stablish limits for the ductility factor based on the desirable performance. In case it is desirable to design the elements in domain 3 , with the relative neutral axis position between the limits from domain 2 and the maximum recommended by the Brazilian standard for concretes of group I, which means $0,259 \leq \beta_{x} \leq 0,450$, it should be adopted the ductility factor between 2,07 and 4,83 . This allows the comparison between the traditional model and the proposed one, based on different parameters. However, it can be seen total agreement between the design of elements analysed with both methods, indicating that the proposed formulation gets the same results in terms of tensile longitudinal reinforcement area, effective depth of the cross section and relative neutral axis position defined by the traditional approach;

- The higher the ductility factor is, the less is the neutral axis relative position and, consequently, for simple reinforcement, higher will be the effective depth of the cross section and smaller longitudinal reinforcement area. This behaviour demonstrated according to the proposed model agrees with is already known about ductility of reinforced concrete elements in simple flexure.

\section{Acknowledgment}

To Sao Paulo Research Foundation (FAPESP), process number 2016/14450-6, for the financial support for this research and this work, and Sao Paulo State University - UNESP.

\section{References}

[1] AMERICAN CONCRETE INSTITUTE. Building Code Requirements for Structural Concrete (ACI 318-95) and Commentary (ACI 318R-95). Detroit, 1995.

[2] ASSOCIAÇÃO BRASILEIRA DE NORMAS TÉCNICAS. NBR 6118 - Projeto de estruturas de concreto - procedimento. Rio de Janeiro, 2014.

[3] BASTOS, PAULO SÉRGIO DOS SANTOS. Flexão Normal Simples - Vigas. Universidade Estadual Paulista. Bauru, 2015.

[4] EUROPEAN COMMITTEE FOR STANDARDIZATION. Eurocode 2: Design of Concrete Structures - Part 1-1: General rules and rules for buildings, December, 2004.

[5] KARA, I. F.; ASHOUR, A. F. Moment redistribution in continuous FRP reinforced concrete beams. Construction and Building Materials, v. 49, p. 939-948, 2013.

[6] KENT, D. C.; PARK, R. Flexural members with confined concrete. ASCE Proceedings, v. 97, n. ST7, p. 19691990, 1971.

[7] KO, M. Y.; KIM, S. W.; KIM, J. K. Experimental study on the plastic rotation capacity of reinforced high strength concrete beams. Materials and Structures, v. 34, n. 5 , p. 302-311, 2001.

[8] LEE, T-K.; PAN, A. D. E. Estimating the relationship between tension reinforcement and ductility of reinforced concrete beam sections. Engineering Structures, v. 25, p. 1057-1067, 2003.

[9] LOPES, A. V.; LOPES, S. M. R.; CARMO, R. N. F. Effect of the compressive reinforcement buckling on the ductility of RC beams in bending. Engineering Structures, v. 37, p. 14-23, 2012.

[10] NOGUEIRA, C.G.; RODRIGUES, I.D. Ductility analysis of $\mathrm{RC}$ beams considering the concrete confinement effect produced by the shear reinforcement: a numerical approach. Latin American Journal of Solids and Structures, v. 14, p. 2343-2372, 2017.

[11] OEHLERS, D. J. Ductility of FRP plated flexural members. Cement and Concrete Composites, v. 28, n. 10, p. 898-905, 2006.

[12] OEHLERS, D.J.; GRIFFITH, M.C.; MOHAMED ALI, M.S. Ductility components and limits of FRP-plated structures. Construction and Building Materials, v. 23, n. 4, p. 15381543, 2009.

[13] OEHLERS, D.J.; VISINTIN, P.; HASKETT, M.; SEBASTIAN, W.M. Flexural ductility fundamental mechanisms governing all RC members in particular FRP RC. Construction and Building Materials, v. 49, p. 985-997, 2013.

[14] PANAGIOTAKOS, T. B.; FARDIS, M. N. Deformations of reinforced concrete members at yielding and ultimate. Structural Journal, v. 98, n. 2, p. 135-148, 2001. 
[15] TENG, J. G.; DE LORENZIS, L.; WANG, B.; LI, R.; WONG, T. N.; LAM, L. Debonding failures of RC beams strengthened with near surface mounted CFRP strips. Journal of composites for construction, v. 10, n. 2, p. 92-105, 2006.

[16] ZIARA, M. M.; HALDANE, D.; KUTTAB, A. S. Flexural behaviour of beams with confinement. ACI Structural Journal, v. 92, n. 1, p. 103-114, 1995.

[17] NOGUEIRA, C.G.; VENTURINI, W.S.; CODA, H.B. Material and geometric nonlinear analysis of reinforced concrete frame structures considering the influence of strength complementary mechanisms. Latin American Journal of Solids and Structures, v. 10, p. 953-980, 2013.

[18] PITUBA, J.J.C.; LACERDA, M.M.S. Simplified damage models applied in the numerical analysis of reinforced concrete structures. IBRACON Structures and Materials Journal v. 5, n. 1, p. 26-37, 2012.

[19] PEREIRA JUNIOR, W.M.; ARAÚJO, D.L.; PITUBA, J.J.C. Numerical analysis of steel-fiber-reinforced concrete beams using damage mechanics. IBRACON Structures and Materials Journal v. 9, n. 2, p. 153-191, 2016.

[20] LEMAITRE, J.; CHABOCHE, J.C. Mechanique des materiaux solides. Paris, Dunod-Bordas, 1985.

[21] MACGREGOR, J.G.; WIGHT, J.K. Reinforced concrete: mechanics and design. Fourth edition, Pearson Prentice Hall, Upper Saddle River, New Jersey, 2005. 